\title{
Pressure compliance of the optic nerve head in low tension glaucoma*
}

\author{
L E PILlUNAT,' R STODTMEISTER,' AND I WILMANNS ${ }^{2}$
}

From the 'University Eye Clinic Ulm, Prittwitzstrasse 43, 7900 Ulm, and the ${ }^{2}$ University Eye Clinic Bonn, Venusberg, 5300 Bonn, Federal Republic of Germany

SUMmary Twenty eyes of 10 healthy subjects, 11 eyes of seven patients with low tension glaucoma, and three eyes of three patients with ischaemic optic neuropathy were investigated. Visual evoked responses were recorded under stepwise artificially increased intraocular pressures. The results of the visual evoked response recording (pressure compliance test) allow a clear distinction to be made between healthy subjects, patients with low tension glaucoma, and patients with ischaemic optic neuropathy. In the groups investigated a lack of autoregulation of the optic nerve head circulation was found in patients with low tension glaucoma only. Patients with anterior ischaemic optic neuropathy showed the same pressure compliance behaviour as healthy subjects. The methods used here seem to provide a practicable clinical tool in the differential diagnosis of low tension glaucoma.

Discussion on the aetiology of low tension glaucoma started in 1862, when von Graefe ${ }^{1}$ for the first time observed a glaucomatous atrophy of the optic nerve head without a rise in intraocular pressure. Since then a variety of pathogenetic concepts have been discussed. Opinions are still controversial, especially with regard to the vascular origin of low tension glaucoma.

Walker et al. ${ }^{2}$ examined the hypothesis that generalised ischaemic vascular diseases may lead to an aspect of low tension glaucoma via a reduced blood supply. However, he did not find the interrelations to be statistically significant. The question has also been considered whether stenosis of the vessels supplying the brain might be causally connected with the eye disease. ${ }^{34}$ In 1952 Etzikson $^{3}$ suggested a pathogenetic relation between radiologically detectable stenosis of the internal carotid artery and low tension glaucoma. Drance et al. ${ }^{45}$ shared this opinion as regards unilateral stenosis of the carotid artery with equilateral low tension glaucoma, but Chandler and $\mathrm{Grant}^{6}$ did not observe any connection between the two conditions. In 1973 Drance et al. ${ }^{5}$ determined

*Presented in part at the meeting of the Swiss Ophthalmological Society, 1985.

Correspondence to Dr Lutz E Pillunat, University Eye Clinic Ulm, Prittwitzstr. 43, 7900 Ulm, Federal Republic of Germany. the blood pressure in the ophthalmic artery by means of impression ophthalmodynamometry. They thus discovered a reduction of the perfusion (in relation to the blood pressure of the upper arm) in patients with low tension glaucoma by comparison with those having primary open angle glaucoma (POAG) and normal persons. Hager ${ }^{7}$ obtained similar results by means of ophthalmodynamography.

Before diagnosing low tension glaucoma, various possible factors should be excluded. Intracranial diseases (tumours, etc.) and ischaemic diseases of the optic nerve might imitate glaucomatous atrophy of the optic nerve and scotomas. As generally accepted, rigidity reductions of the sclera in myopia cause intraocular pressures which appear too low if they are measured by impression tonometry; the condition may therefore imitate low tension glaucoma. The problems described and the fact that it is often difficult to diagnose low tension glaucoma lead to the question whether it is possible to obtain indications of the existence and aetiology of low tension glaucoma by a clinically practicable non-invasive method. In recent years several authors ${ }^{89}$ have tried to describe the pressure compliance of the optic nerve head in healthy subjects and in various types of glaucoma. Ulrich and Ulrich' showed, in a single case, by electroencephalodynamography that a lowered pressure compliance of the optic nerve head in low 
tension glaucoma might be suspected. In the study presented here we have investigated patients presenting with the clinical diagnosis of low tension glaucoma. We used an improved method to check the widely accepted hypothesis of lowered pressure compliance of the optic nerve head in this condition.

\section{Subjects and methods}

Seven consecutive patients ( 11 eyes) with low tension glaucoma were examined. The criteria for inclusion were: typical glaucomatous scotomas; intraocular pressure $<21 \mathrm{mmHg}$; normal outflow facility; a cup/disc ratio $>0.7$.

Other diseases which might imitate low tension glaucoma (ischaemic optic neuropathy, intracranial tumours, etc.) were clinically excluded by $x$-rays of the skull, computer tomography, doppler sonography, and digital subtraction angiography of the carotid arteries. Three eyes out of our seven patients could not be examined, as visual acuity was below 20/200.

Three eyes in three patients with clearly delineated clinical ischaemic optic neuropathy were examined. For comparison, 10 healthy subjects ( 20 eyes) were investigated.

All groups were comparable in age and sex (Table 1). In all patients and healthy subjects no treatment affecting intraocular pressure was given. No mydriatics were used. The pressure compliance of the optic nerve head was tested by recording visual evoked responses under stepwise artificially increased intraocular pressures.

The following method was used to record the visual evoked responses. For monocular stimulation, checker board pattern reversal stimuli were applied (reversal rate $15 \mathrm{~Hz}$, motion time $1.5 \mathrm{~ms}$, luminance of the white checks $325 \mathrm{~cd} / \mathrm{m}^{2}$; luminance of the black checks $10 \mathrm{~cd} / \mathrm{m}^{2}$, angular subtense of a single check $27^{\prime}$ of arc; angular subtense of the projection screen $12^{\circ}$; the distance between the eye of the patient and the screen was 7 feet $(2 \cdot 1 \mathrm{~m}))$.

In visual evoked response recording the different electrode was placed in the midline $5 \mathrm{~cm}$ above the inion and the reference electrode $30 \%$ (20/20 system)

Table 1 Distribution of persons by sex and by arithmetic mean of intraocular pressure and age

\begin{tabular}{lccc}
\hline & $\begin{array}{l}\text { Lowtension } \\
\text { glaucoma }\end{array}$ & $\begin{array}{l}\text { Ischaemic } \\
\text { optic } \\
\text { neuropathy }\end{array}$ & $\begin{array}{l}\text { Healthy } \\
\text { subjects }\end{array}$ \\
\hline Eyes & 11 eyes & 3 eyes & 20 eyes \\
Sex & 3 males & 1 male & 5 males \\
Intraocular pressure, mean & $46.4 \mathrm{mmHg}$ & 2 females & 5 females \\
Age, mean & 58 years & 63 years & $17 \cdot 2 \mathrm{mmHg}$ \\
\hline
\end{tabular}

above the root of the nose. The common electrode was placed at the left ear lobe.

Stimulation by this technique evokes potentials which appear in the steady state as signals at a frequency of $15 \mathrm{~Hz}$, corresponding to the repetition frequency of the stimuli and in our measurements with amplitudes varying between 3 and $9 \mu \mathrm{V}$. These signals originate in the calcarine cortex..$^{10}$ The amplitudes of spontaneous brain potentials are much higher, and the signals we are interested in cannot be detected on an oscilloscopic display. The measurement of evoked signals is not easily done with commercial 'AC' meters or recording systems. Among several techniques which permit the detection and measurement of signals buried in noise we chose phase-sensitive or synchronous rectification. This method is based on the fact that the desired signals appear in synchronism with the stimulation frequency. The synchronous rectifier is basically a switch which permits the signals to pass during half of each period of the driving frequency. The passing signal current changes a condenser. The change in level is recorded as a function of time. The input resistance of the recorder discharges the condenser continuously. The combined effect of the charging and discharging leads to a recorded charge level which is proportional to the desired signals.

The spontaneous brain potentials have no component at the stimulation frequency. Thus their average value is zero. Their remaining contribution to the recorded signal is theoretically infinitely small. In practice it is kept insignificant by choosing the proper time constant for the recording system without making the response time too long. If there is a delay between the stimulation and the appearance of the evoked potentials, there is still synchronism with the stimulation frequency, but the phase of the evoked signal with respect to the stimulation signal is stuffed. If the phase shift approaches $90^{\circ}$ or multiples of these, the evoked signals will not be recorded. Their average value is then zero. If we use a second synchronous rectifier with the same signal at the input but with a switching signal shifted by $90^{\circ}$, compared with the stimulation frequency (which can be easily done with a phase shifter) the phase shifted part of the evoked signal will be recorded in this second channel. It will be recorded at full amplitude if the phase shift is exactly $90^{\circ}$. For all evoked signals with intermediate phase shifts the time amplitude is calculated as the square root of the sum of the squares of the recorded signals with $0^{\circ}$ and $90^{\circ}$ phase shifts, as there will be components in both channels. The phase shift is found as the arc tangent of the ratio of the components with $0^{\circ}$ and $90^{\circ}$ phase shift.

The measuring and recording system can be considered as a unit and calibrated with signals which are 
injected into the electrode circuit connecting the electrodes on the patient with the measuring system. These signals can be varied in amplitude and phase and are derived from the stimulation frequency. In this way the calibration signal is automatically at all times in synchronism with the stimulation.

The test signal undergoes exactly the same treatment as the signals due to the evoked potentials. ${ }^{11}$ In addition the test signal is covered by noise due to the spontaneous brain potentials and, possibly, external noise sources in the same way as the evoked signal. Thus any deterioration of the signals can be easily found and its effects can be exactly measured. The entire system can be tested at any time and faulty electrode connections spotted and corrected immediately.

The visual evoked responses were recorded monocularly without an artificial rise of intraocular pressure. Afterwards the intraocular pressure was increased stepwise artificially by the suction cup method $^{12}$ with a standardised suction cup.

The following pressure steps were applied: 80,130 , $160,200,250,300,350 \mathrm{mmHg}$ of negative pressure. The conversion of the applied negative pressures to increased intraocular pressure (IOP) values involved use of the regression curves according to Hayatsu. ${ }^{13-15}$ Because the regression curves were made for healthy eyes we applied a negative pressure by a suction cup in three patients with low tension glaucoma and in two patients with ischaemic optic neuropathy. We then measured the intraocular pressure by applanation tonometry. In this test we could not find any striking difference in the IOP values in the regression curves. We therefore feel justified in using the regression curves according to Hayatsu also in our patients with low tension glaucoma and ischaemic optic neuropathy.

The visual evoked response amplitudes were then plotted against the intraocular pressure.

Owing to the well known high variation of visual evoked response amplitude between individuals, the measured amplitudes are given as a percentage of the response amplitude of the visual evoked response recorded without artificially increased intraocular pressures, which is set as $100 \%$. (The absolute values in microvolts are given in Table 2.)

Table 2 Arithmetic mean and standard deviation of VER amplitudes

\begin{tabular}{ccll}
\hline & $\begin{array}{l}\text { Low tension } \\
\text { glaucoma }\end{array}$ & $\begin{array}{l}\text { Ischaemicoptic } \\
\text { neuropathy }\end{array}$ & Healthy subjects \\
\hline Maximum VER amplitude: & & \\
mean & $4 \cdot 82 \mu \mathrm{V}=100 \%$ & $4 \cdot 11 \mu \mathrm{V}=100 \%$ & $4 \cdot 7 \mu \mathrm{V}=100 \%$ \\
SD & $\pm 0 \cdot 3 \mu \mathrm{V}$ & $\pm 0 \cdot 2 \mu \mathrm{V}$ & $\pm 0.4 \mu \mathrm{V}$ \\
\hline
\end{tabular}

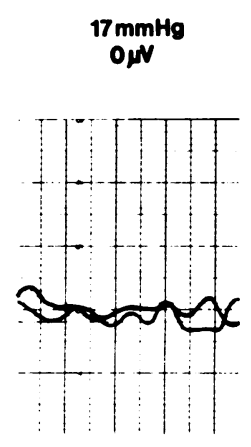

A
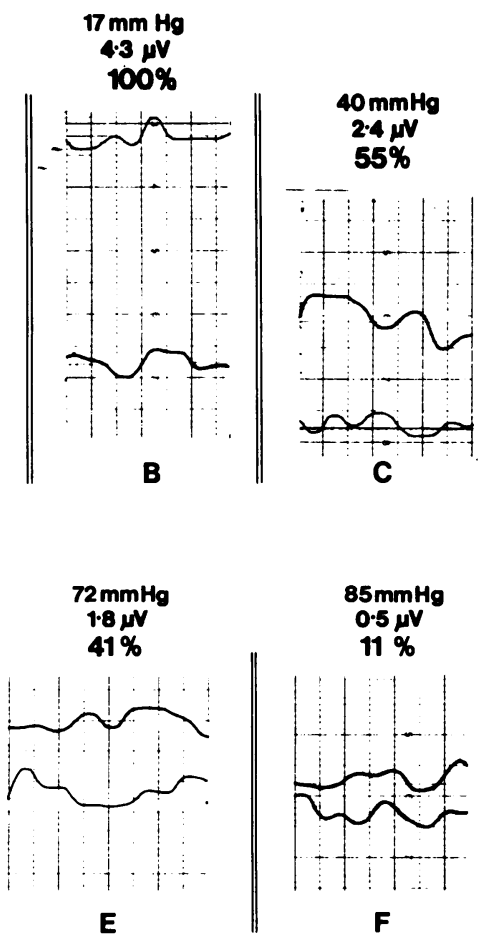

Fig. 1 Original VER recordings of a healthy subject. The thick line represents the channel-1 output of the phase sensitive detector (PSD) and the thin line represents the channel 2 output. The phase angle between these two channels is exactly $90^{\circ}$. In the first recording $(A)$ the checkerboard reversal is switched off, i.e., there is no stimulus. Thus recording $A$ represents the baseline. In recordings $B$ to $F$ the checkerboard reversal stimulus is applied. Recordings $A$ and $B$ were registered at uninfluenced intraocular pressure $(17 \mathrm{mmHg})$ and recordings $C-F$ were registered at artificially increased intraocular pressures $(40-85 \mathrm{mmHg})$. The deviations of the output recordings from the baseline (recording $A$ ) represents the output changes due to stimulation at uninfluenced intraocular pressure (recording $B$ ) and at artificially increased intraocular pressure (recordings $C-F)$. 


\section{Results}

Figs. 1 and 2 show original recordings of the outputs of both channels on the strip chart recorder. Each recording section marked by an upper case letter shows the output of each channel during a time span of about 20 seconds. The sections were recorded successively. During certain intervals in the recording sections (marked by double lines) the subjects and the patients were allowed to generate artefacts by head movements. These intervals of about 10 seconds are not shown because they provide no information. For the recording sections $\mathrm{A}$ in Figs. 1 and 2 the subjects or patients looked at a checkerboard pattern which did not reverse-that is, the stimulus, the pattern reversal, was switched off. Thus the recording section $A$ represents the base line. At the recording sections $B$ in Figs. 1 and 2 the pattern reversal took place whereby the intraocular pressure was uninfluenced. The amplitude of the evoked potentials, indicated at each recording section below the intraocular pressure, is calculated from the absolute amplitude values as shown on the recordings and represents the normal value for the subject or the patient.

The intraocular pressure was artificially increased during the recording sections $C$ through $F$ in Fig. 1 and $C$ through $E$ in Fig. 2 respectively. The value of the intraocular pressure during these recording sections is given in the uppermost line above the recording sections. The calculated amplitudes are given below. We take the amplitudes of section B (at uninfluenced intraocular pressure) as the $100 \%$ value and indicate the amplitude values at increased intraocular pressure as percentages of the amplitude of
Section B. The arithmetic mean and the standard deviation of the VER amplitudes are shown in Figs. 3,4 , and 5, plotted against the intraocular pressure. We measured only for certain pressure values. The curves shown in Figs. 3, 4, and 5 are called amplitude/ pressure curves. They are drawn by connecting the measured points by straight lines.

The visual evoked response amplitudes plotted against the actual intraocular pressures of 20 healthy normotensive eyes are shown in Fig. 3. The slope of the curve is not uniform. For the first step increase of the intraocular pressure the amplitude is halved. The amplitude is almost constant for pressures up to 60 mmHg. It then decreases linearly to the residual noise level which is reached for a pressure of approximately $85 \mathrm{mmHg}$.

The amplitude/pressure curve (Fig. 4) for eyes with low tension glaucoma does not show an intermittent plateau. It decreases linearly to the noise level, which is reached at an intraocular pressure of $60 \mathrm{mmHg}$. In ischaemic optic neuropathy the amplitude pressure curve shows the intermittent plateau as seen in healthy subjects and reaches the noise level at about $80 \mathrm{mmHg}$ intraocular pressure - a value similar to that in healthy subjects. The absolute visual evoked response amplitudes in microvolts are practically equal in healthy subjects and in patients with low tension glaucoma. The maximum amplitudes (Table 2) for patients with ischaemic optic neuropathy are approximately $0.75 \mu \mathrm{V}$ lower than in the two other groups.

\section{Discussion}

The analysis of transient visual evoked potentials is

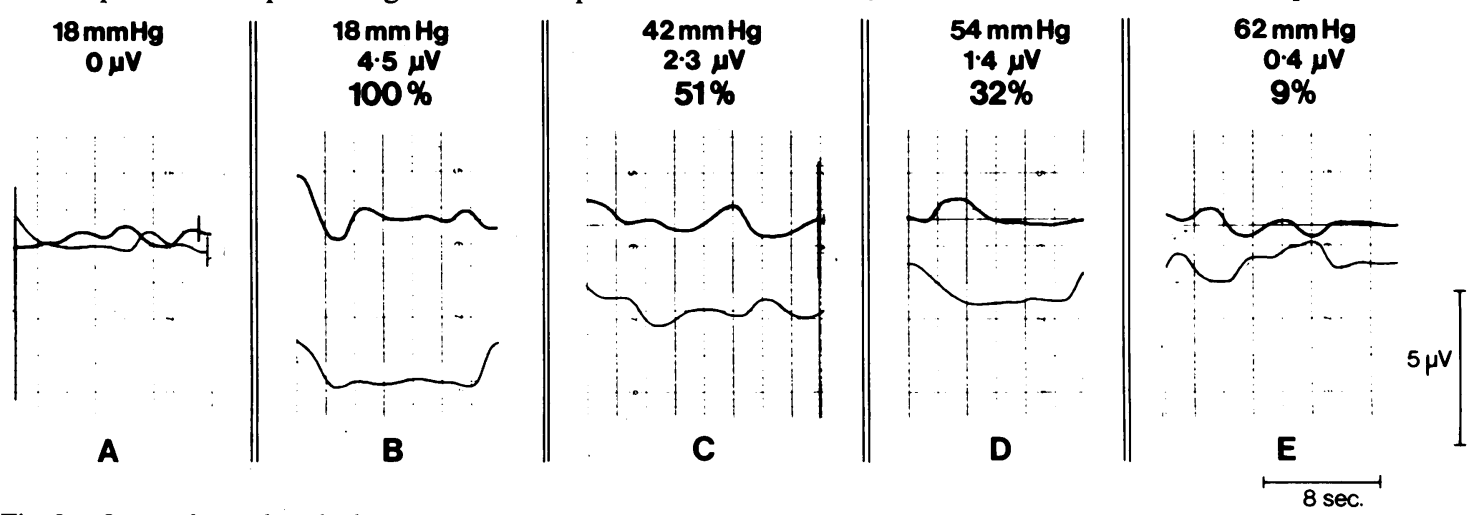

Fig. 2 Original visual evoked response (VER) of a patient with low tension glaucoma (first row: intraocular pressure; second row: absolute VER amplitude in microvolts; third row: relative VER amplitude in percent). Recordings of the output from the phase sensitive detector. The thick line represents the output of channel 1 (phase angle $0^{\circ} ; \mathrm{CH}_{\text {al }}$ ) and the thin line that of channel 2 (phase angle $90^{\circ} ; \mathrm{CH}_{a 2}$ ). From the left: 1st recording $(A)$-base line from the unaffected eye (without stimulus). 2nd recording $(B)$-recording from the unaffected eye (checkerboard stimulus applied: reversal rate $15 \mathrm{~Hz}$; motion time $1.5 \mathrm{~ms}$; angular subtense of a single check 27' of arc). 3rd to 5 th $(C-E)$ recording-recordings with artificially increased intraocular pressures. 


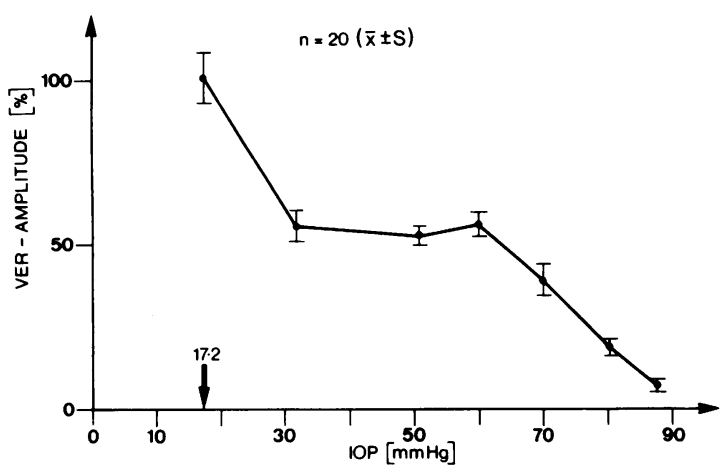

Fig. 3 Visual evoked response amplitude of 20 healthy eyes plotted against the intraocular pressure. $(17.2 \mathrm{mmHg}=I O P$ of the unaffected eyes).

today the most widely used method in clinical and experimental studies. It seems to provide the most information about the problems under investigation. Transient evoked potentials have the additional advantage that we can easily correlate the formation process and the results of measurement. However, the evaluation of transient visual evoked responses does have drawbacks. We bore in mind that the continuous recording of a transient visual evoked potential obtained with ordinary commercial instruments contains no information on the effects of input noise. This information, however, is important:

Transient evoked potential curves are a sequence of arithmetic means. The information content of an arithmetic mean is limited if the distribution of the single values is not known. ${ }^{16}$ In recording transient evoked potentials it is in addition assumed that the noise of the disturbing signals is 'white'. This is not true: Stodtmeister et al. ${ }^{17}$ showed that the transient evoked potentials are to some extent influenced by forced synchronisation of the alpha rhythm.

A further problem with transient evoked poten-

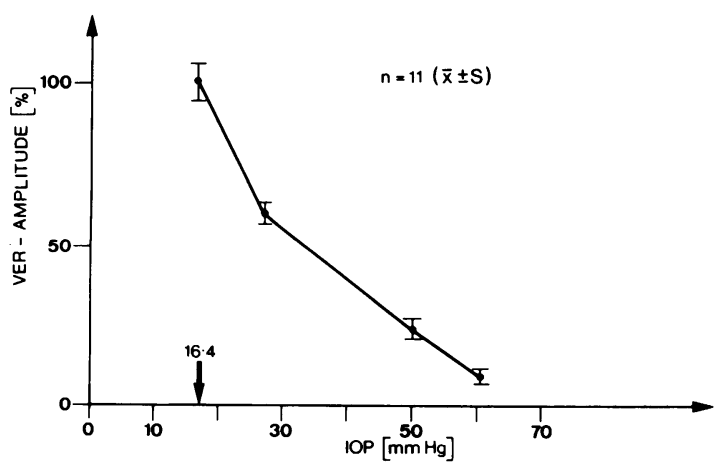

Fig. 4 Visual evoked response amplitude of 11 eyes with low tension glaucoma plotted against the intraocular pressure. $(16.4 \mathrm{mmHg}=I O P$ of the unaffected eyes $)$.

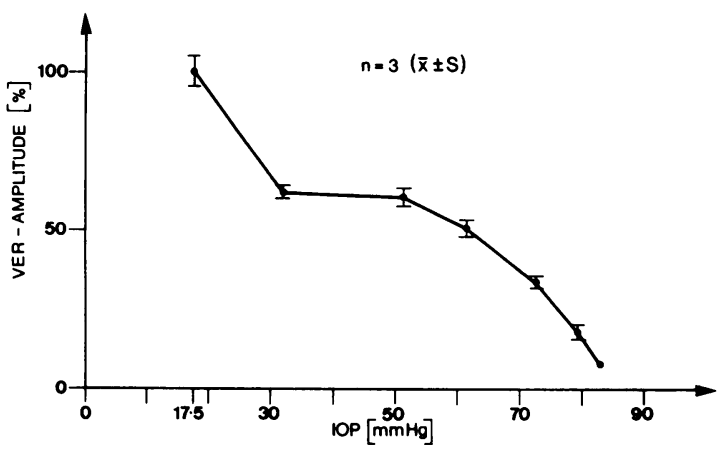

Fig. 5 Visual evoked response amplitude of three eyes with ischaemic optic neuropathy plotted against the intraocular pressure. $(17.5 \mathrm{mmHg}=$ IOP of the unaffected eyes).

tials is that the recording time is relatively long (approximately 30-60 seconds). In this study we recorded the visual evoked potentials by a fast method because artificial increase in intraocular pressure accelerates the outflow of aqeuous humour. The method of phase sensitive detection has been used by other authors quite successfully. ${ }^{18-20} \operatorname{Regan}^{20}$ has pointed out in a basic article that the analysis of steady state evoked potentials by phase sensitive detection is a very suitable tool for evaluating the function of the visual system. We used this method because it is fast and more sensitive than averaging methods, and the measurement is straightforward. An additional reason for using this method is that the influence of the noise on the signals can be derived from the recordings, and a special advantage of it is the ease of calibration of the entire system, including the electrodes. Thus we believe that phase sensitive detection is a valuable and trustworthy tool in the clinical examination of patients for glaucoma. Owing to individual anatomical conditions the position of the macular projection in the calcarine cortex differs slightly in each individual. This causes considerable differences between individuals in the amplitudes of the visual evoked responses. We have taken the quiescent amplitude as $100 \%$ for each amplitude/ pressure curve and expressed the remaining values as a percentage of the quiescent values. The relative amplitude/pressure curves are quite uniform for the different groups which we examined.

The visual evoked response amplitudes as a sign of optic nerve head function do not decrease continually (Fig. 3) but remain almost constant for an intermediate pressure range. We have described this behaviour in younger subjects, ${ }^{21}{ }^{22}$ and we observed it also in the older subjects presented here. The plateau in the amplitude/intraocular pressure curve has been interpreted as an indication of autoregulation. We therefore assume that autoregulation still works in 
healthy subjects of a more advanced age. The patients with low tension glaucoma, however, do not show this plateau in the amplitude/pressure curve, whereas those patients with ischaemic optic neuropathy do show an intermittent plateau. This result leads to the conclusion that there are two different pathogenetic processes in these two diseases, which are not always clinically distinguishable.

Anderson ${ }^{23}$ mentioned difficulties in attempting to explain low tension glaucoma with respect to primary open angle glaucoma. This is because in low-tension glaucoma there is no increased intraocular pressure which may lead to a mechanically induced damage of the optic nerve head. But the damage in low tension glaucoma and in primary open angle glaucoma is comparable. Therefore Anderson ${ }^{23}$ suggests a lack of autoregulation in primary open angle glaucoma and in low tension glaucoma as the common pathogenetic factor. There is an increasing amount of evidence that auroregulation of ocular blood flow in the optic nerve head takes place. It can be demonstrated by different methods and in different species as well as in man. ${ }^{24-27}$

The lack of autoregulation has been suggested by Anderson ${ }^{23}$ and by Robert and Maurer ${ }^{26}$ as a pathogenetic factor in the development of damage in low tension glaucoma and primary open angle glaucoma. From our results we consider that such lack of autoregulation can be confirmed. Furthermore, the amplitude/intraocular pressure curves in low tension glaucoma, ischaemic optic neuropathy, and in healthy subjects do not differ only in relation to autoregulation.

It can also be seen that the critical pressure in low tension glaucoma is reached at lower intraocular pressure values than in patients with ischaemic optic neuropathy and healthy subjects. In this context we define 'critical pressure' as that pressure for which visual evoked response amplitudes reach the noise level. In our recording system the base line noise is about 300 nanovolts, corresponding to about $10 \%$ of the initial visual evoked response amplitude. Thus this low critical intraocular pressure and the lack of autoregulation described can be interpreted as a lowered pressure compliance of the optic nerve head in low tension glaucoma, and this lowered pressure compliance may be the origin of optic nerve damage.

Comparison of the critical intraocular pressures in low tension glaucoma and in ischaemic optic neuropathy shows that this pressure is higher in ischaemic optic neuropathy than in low tension glaucoma (Figs. 4 and 5). This result confirms the suggestion, backed by clinical experience, that low tension glaucoma and ischaemic optic neuropathy are distinct entities.

Previous results ${ }^{22}$ have shown that in patients with primary open angle glaucoma there is no sign of autoregulation in the VER amplitude/pressure curves. This finding appears to be similar to those presented here in patients with low tension glaucoma. But the 'critical pressure'-that is, the intraocular pressure for which the visual evoked response amplitudes disappear in the noisecorresponds in these cases to an intraocular pressure of about $80 \mathrm{mmHg}$. Thus the suggestion is confirmed that primary open angle glaucoma and low tension glaucoma are the same disease, but in low tension glaucoma the 'critical pressure' is lower, which means that the pressure compliance of the optic nerve head is lower.

According to Richardson ${ }^{28}$ it is probably best to assume - as with most human ailments-glaucoma will prove to be a disease where lack of resistance to force is more important than the force itself.' Previous results ${ }^{2122}$ and those reported here may be interpreted in the same way. We believe that the 'lack of resistance' noted by Richardson can be confirmed by the methods used here.

Referring to animal studies Sossi and Anderson ${ }^{25}$ and Anderson and Davis ${ }^{29}$ supposed that an important factor in glaucoma damage is the lack of autoregulation. Our results show that the lack of autoregulation is an important factor in low tension glaucoma. It is widely suspected that the pressure compliance of the optic nerve head is lowered in low tension glaucoma. We believe that it is possible to carry out a clinically practicable determination of this lowered pressure compliance by the method used here.

\section{References}

1 Graefe A von. Über die glaukomatöse Natur der Amaurose mit Sehnervenexcavation und über das Wesen und die Classifikation des Glaukoms. Graefes Arch Clin Exp Ophthalmol 1862; 8: 271-97.

2 Walker WM, Walton KW, Magnani HN. Glaucoma and ischaemic vascular disease risk factors. Trans Ophthalmol Soc UK 1976; 96: 237-40.

3 Etzikson LJ. Calcification of basal arteries and so called pseudoglaucoma. Vestn Oftalmol 1952; 31: 7-11.

4 Drance SM. Some factors in the production of low tension glaucoma. Br J Ophthalmol 1972; 56: 229-42.

5 Drance SM, Sweenly VP, Morgan RW, Feldmann F. Studies of factors involved in the production of low tension glaucoma. Arch Ophthalmol 1973; 89: 457-65.

6 Chandler PA, Grant WM. Glaucoma. Philadelphia: Lea and Febiger, 1979: 111-5.

7 Hager H. Differential diagnosis of apoplexy by ophthalmodynamometry. Triangle 1964; 6: 259-67.

8 Bartl G. Das Elektroretinogramm und das evozierte Sehrindenpotential bei normalen und an Glaukom erkrankten Augen. Graefes Arch Clin Exp Ophthalmol 1978; 207: 243-69.

9 Ulrich WD, Ulrich C. An electrophysiological approach to the diagnosis and treatment of glaucoma. Dev Ophthalmol 1984; 9: $140-6$.

10 Regan D. Rapid objective refraction using evoked brain potentials. Invest Ophthalmol Vis Sci 1973; 12: 669-79. 
11 Wilmanns I, Stodtmeister R. Ein neues Verfahren zur Kalibrierung elektrophysiologischer Untersuchungseinheiten. Graefes Arch Clin Exp Ophthalmol 1977; 205: 33-6.

12 Mikuni M, Iwata K. Mikuni's ophthalmodynamometer. Acta Med Biol 1965; 12: 279-88.

13 Hayatsu $\mathrm{H}$. Measurement of blood pressure in retina, especially on calibration curves for Mikuni's ophthalmodynamometer. $\mathbf{I}$. Calibration curves by Schiøtz's standardized tonometer. Nippon Ganka Gakkai Zasshi 1964; 68: 111-9.

14 Hayatsu $\mathrm{H}$. Measurement of blood pressure in retina, especially on calibration curves for Mikuni's ophthalmodynamometer. II. Calibration curves by Goldmann's applanation tonometer. Nippon Ganka Gakkai Zasshi 1964; 68: 175-80.

15 Hayatsu $H$. Measurements of blood pressure in retina, especially on calibration curves for Mikuni's ophthalmodynamometer. III. Influences of age, refraction and ocular rigidity upon calibration curves. Nippon Ganka Gakkai Zasshi 1964; 68: 247-55.

16 Sokal RR, Rohlf FJ. Introduction to biostatistics. San Francisco: Freeman, 1973.

17 Stodtmeister R, Wilmanns I, Baur M. Einfluss nichtperiodischer Reize auf die Variabilität visuell evozierter kortikaler Potentiale. Dev Ophthalmol 1981; 3: 194-215.

18 Fricker SJ. Application of synchronous detector techniques for electroretinographic studies in patients with retinitis pigmentosa. Invest Ophthalmol Vis Sci 1971; 10: 329-39.

19 Padmos P, van Norren D. The vector voltameter as a tool to measure electroretinogram spectral sensitivity and dark adaption. Invest Ophthalmol Vis Sci 1972; 11: 783-8.

20 Regan D. Comparison of transient and steady-state methods. Ann NY Acad Sci 1982; 338: 45-71.
21 Pillunat LE, Stodtmeister R, Wilmanns I, Christ T. New aspects in pressure tolerance of the optic nerve head. Invest Ophthalmol Vis Sci 1985; 26(suppl): 223.

22 Pillunat LE, Stodtmeister R, Wilmanns I, Christ T. Autoregulation of ocular blood flow during changes of intraocular pressure. Preliminary results. Graefes Arch Clin Exp Ophthalmol 1985; 223: 219-23.

23 Anderson DR. The posterior segment of glaucomatous eyes. In: Lütjen-Drecoll E, ed. Basic aspects of glaucoma research. Stuttgart, New York: Schattauer, 1982: 167-81.

24 Geijer C, Bill A. Effects of raised intraocular pressure on retinal, prelaminar, laminar and retrolaminar optic nerve blood flow in monkeys. Invest Ophthalmol Vis Sci 1979; 18: 1030-42.

25 Sossi N, Anderson DR. Effect of elevated intraocular pressure on blood flow. Occurrence in cat optic nerve head studied with 125-iodoantipyrine. Arch Ophthalmol 1982; 101: 98-101.

26 Robert Y, Maurer W. Pallor of the optic disc in glaucoma patients with artificial hypertension. Doc Ophthalmol 1984; 57: 203-14.

27 Richard G. Beeinflussung der retinalen Hämodynamik durch Änderung des Augeninnendruckes: eine videoangiographische Studie. Ophthalmologica 1985; 190: 199-204.

28 Richardson KT. Glaucoma and glaucoma suspects. In: Heilmann K, Richardson KT, eds. Glaucoma-conceptions of a disease. Stuttgart: Thieme, 1978: 2-25.

29 Anderson DR, Davis EB. Retina and optic nerve after posterior ciliary artery occlusion. An experimental study in squirrel monkeys. Arch Ophthalmol 1974; 92: 422-6

Accepted for publication 29 May 1985. 